\title{
Inflow Jet Patterns of Unruptured Cerebral Aneurysms Based on the Flow Velocity in the Parent Artery: Evaluation Using 4D Flow MRI
}

\author{
(D). Futami, (D). Kitabayashi, (D) H. Sano, (D). Misaki, (DN. Uchiyama, (D). Ueda, and (D). Nakada
}

\begin{abstract}
BACKGROUND AND PURPOSE: Inflow jet characteristics may be related to aneurysmal bleb formation and rupture. We investigated the visualization threshold on the basis of the flow velocity in the parent artery to classify the inflow jet patterns observed on 4D flow MR imaging.

MATERIALS AND METHODS: Fifty-seven unruptured aneurysms (24 bifurcation and 33 sidewall aneurysms) were subjected to 4D flow MR imaging to visualize inflow streamline bundles whose velocity exceeded visualization thresholds corresponding to $60 \%, 75 \%$, and $90 \%$ of the maximum flow velocity in the parent artery. The shape of the streamline bundle was determined visually, and the inflow jet patterns were classified as concentrated, diffuse, neck-limited, and unvisualized.

RESULTS: At the 75\% threshold, bifurcation aneurysms exhibited a concentrated inflow jet pattern at the highest rate. At this threshold, the inflow jets were concentrated in 13 aneurysms (group C, 22.8\%), diffuse in 18 (group D, 31.6\%), neck-limited in 11 (group N, 19.3\%), and unvisualized in 15 (group U, 26.3\%). In 16 (28.1\%) of the 57 aneurysms, the inflow jet pattern was different at various thresholds. Most inflow parameters, including the maximum inflow velocity and rate, the inflow velocity ratio, and the inflow rate ratio, were significantly higher in groups $C$ and $D$ than in groups $\mathrm{N}$ and $\mathrm{U}$.
\end{abstract}

CONCLUSIONS: The inflow jet pattern may depend on the threshold applied to visualize the inflow streamlines on 4D flow MR imaging. For the classification of the inflow jet patterns on 4D flow MR imaging, the 75\% threshold may be optimal among the 3 thresholds corresponding to $60 \%, 75 \%$, and $90 \%$ of the maximum flow velocity in the parent artery.

$\mathrm{T}$ he inflow jets of cerebral aneurysms have been characterized as flow structures composed of strongly directed inflow with higher speeds than in other parts of the aneurysm. ${ }^{1,2}$ Computational fluid dynamics analyses by using human cerebral aneurysm models suggested that inflow jets may be related to bleb formation and aneurysmal rupture. ${ }^{3-5}$ Cebral et $\mathrm{al}^{3}$ reported that most blebs formed at sites where the inflow jet impacted the aneurysmal wall, and they qualitatively classified the inflow jets of ruptured and unruptured cerebral aneurysms into concentrated and diffuse inflow jets. ${ }^{3-5}$ They found that most ruptured aneurysms featured concentrated inflow jets, while diffuse inflow jets tended to be seen in unruptured an-

Received August 7, 2015; accepted after revision December 16.

From the Department of Neurosurgery, Mattoh-Ishikawa Central Hospital (K.F.), Ishikawa, Japan; and Departments of Neurosurgery (T.K., H.S., K.M., N.U., M.N.) and Radiology (F.U.), Kanazawa University School of Medicine, Ishikawa, Japan.

Please address correspondence to Kazuya Futami, MD, Department of Neurosurgery, Mattoh-Ishikawa Central Hospital, 3-8 Kuramitsu, Hakusan, 920-8588 Ishikawa, Japan; e-mail: kfutami@mattohp.com

http://dx.doi.org/10.3174/ajnr.A4704 eurysms. ${ }^{4,5}$ This finding suggests that bleb formation and aneurysm rupture may be attributable to a degenerative change in the aneurysm wall exposed to the increased hemodynamic stress exerted by the inflow jet. Therefore, the assessment of inflow jet patterns and quantitative estimation of the inflow hemodynamics may contribute to a more precise prediction of the risk for bleb formation and aneurysm rupture.

Computational fluid dynamics analysis uses human aneurysm models based on a number of assumptions and approximations regarding blood properties, vessel wall compliance, and flow conditions. ${ }^{3-8}$ For the quantitative evaluation of the hemodynamics in real human cerebral aneurysms, $4 \mathrm{D}$ flow MR imaging, which is based on time-resolved 3D cine phase-contrast MR imaging techniques, has been used. ${ }^{9-20}$ In this study, we investigated the visualization threshold on the basis of the flow velocity in the parent artery to classify the inflow jet patterns of unruptured cerebral aneurysms on 4D flow MR imaging. We applied different thresholds to visualize the inflow streamlines, evaluated the inflow jet patterns, and examined the relationship between the inflow jet pattern and the inflow hemodynamics. 


\section{MATERIALS AND METHODS}

This study was approved by the ethics committee of MattohIshikawa Central Hospital. Prior written informed consent was obtained from all patients.

\section{Materials}

We acquired 4D flow MR images in 68 patients with 72 unruptured cerebral aneurysms. Excluded from our study were 7 aneurysms whose poor-quality images were inadequate for evaluation due to motion artifacts ${ }^{21}$ during the systole phase of the cardiac cycle and 8 aneurysms with a maximum diameter of $<4.0 \mathrm{~mm}$ or a neck size of $<2.0 \mathrm{~mm}$ because the spatial resolution is limited on 4D flow MR imaging. ${ }^{20,22}$ Consequently, this study included 53 patients ( 22 men, 31 women) ranging in age from 51 to 86 years (mean, $71.6 \pm 9.0$ years) with 57 unruptured cerebral aneurysms ( 24 bifurcation and 33 sidewall aneurysms). Of the aneurysms, 4 were located on the cavernous, and 15 , on the paraclinoid segment of the ICA; 14, on the ICA segment branching the posterior communicating artery; 1 , on the ICA bifurcation; 6 , on the bifurcation of the anterior cerebral artery and the anterior communicating artery; 14, on the MCA bifurcation; and 3, on the basilar artery bifurcation. The maximum diameters of the aneurysms and their neck sizes were $6.8 \pm 3.1 \mathrm{~mm}$ (range, $4.0-17 \mathrm{~mm}$ ) and $5.0 \pm 2.2 \mathrm{~mm}$ (range, $2.0-13.7 \mathrm{~mm}$ ), respectively.

\section{MR Imaging}

MR imaging was performed on a 1.5T scanner (Magnetom Avanto; Siemens, Erlangen, Germany) with a slew rate of 125 $\mathrm{T} / \mathrm{m} / \mathrm{s}$ and an 8 -channel head array coil. The vascular geometry was assessed on 3D TOF MRA. The scanning parameters were TR/TE/NEX, 35 ms/7.15 ms/average 1; flip angle, $22^{\circ}$; FOV, $150 \times$ $123 \mathrm{~mm}$; z-coverage, $45.6 \mathrm{~mm}$; 0.6-mm thickness; 3 slabs; $30 \mathrm{sec}-$ tions/slab; slab interval, $-4.2 \mathrm{~mm}$ (ie, overlapping slab acquisition, $4.2 \mathrm{~mm})$; matrix, $256 \times 168(512 \times 336$ with zero-filling interpolation processing); voxel size, $0.59 \times 0.73 \times 0.6 \mathrm{~mm}$ $(0.295 \times 0.365 \times 0.6 \mathrm{~mm}$ with zero-filling $)$; bandwidth, $87 \mathrm{~Hz} /$ px; imaging time, 4 minutes 53 seconds; transaxial direction.

Blood flow analysis was performed on 4D flow MR imaging scans. The parameters were TR/TE/NEX, $33.05 \mathrm{~ms} / 5.63 \mathrm{~ms} /$ average 1; flip angle, $22^{\circ}$; FOV, $200 \times 200 \mathrm{~mm}$; 0.8-mm thickness; 1 slab; 24-26 sections/slab; z-coverage, $19.2 \mathrm{~mm}$; matrix, $192 \times$ 192; no interpolation processing; voxel size, $1.04 \times 1.04 \times 0.8$ mm; velocity-encoding, $80 \mathrm{~cm} / \mathrm{s}$; bandwidth, $434 \mathrm{~Hz} / \mathrm{px}$; parallel imaging with reduction factor, 2 ; imaging time, 20-30 minutes depending on the patient's heart rate; transaxial direction; retrospective gating with electrocardiogram; 20 phases. We selected a velocity-encoding of $80 \mathrm{~cm} / \mathrm{s}$ to visualize streamlines whose velocity exceeded a chosen visualization threshold based on the maximum flow velocity in the parent artery.

On the basis of the 3D TOF MRA datasets, the vascular wall was constructed by using the region-growing method ${ }^{23}$ and the "Marching Cubes" method. ${ }^{24}$ The 3D datasets obtained by $4 \mathrm{D}$ flow MR imaging were converted to pixel datasets at a spatial resolution of $0.5 \times 0.5 \times 0.5 \mathrm{~mm}$ by using a function featured on commercially available software (Flova II, Version 2.9.15.0; R'tech, Hamamatsu, Japan) to visualize 3D flow information.

\section{Data Analysis}

With a Flova II function, an arbitrary percentage value of the maximum flow velocity in the parent artery can be selected as the visualization threshold. We set $60 \%, 75 \%$, and $90 \%$ as the thresholds to evaluate the role they play in the visualization of the inflow jet patterns. The inflow jet was visualized as a bundle of streamlines whose velocity exceeded the threshold at the aneurysmal orifice. The 57 aneurysms were classified by visual inspection into 4 groups based on the shape of the streamline bundle and the site on the aneurysmal wall impacted by the inflow streams (Fig 1). Group C exhibited a concentrated inflow jet with intrusion into the aneurysmal dome without dispersion in $20 \%$ of the width of the streamline bundle at the aneurysmal orifice and an impact at the aneurysm wall at a site half-way up the aneurysm height (Fig 1, Concentrated). Group D comprised aneurysms with a diffuse inflow jet defined as an inflow jet intruding into the aneurysmal dome with dispersion in $>20 \%$ of the width of the streamline bundle at the aneurysm orifice and an impact on the aneurysmal wall at a site more than half-way up the aneurysm height (Fig 1, Diffuse). The $20 \%$ value was chosen to accommodate measurement errors of the width of the inflow streamline bundle. Group $\mathrm{N}$ consisted of aneurysms with neck-limited inflow jets defined as inflow streamlines that impacted the aneurysm wall at a site between the neck and the lower half of the aneurysm height irrespective of the shape of the inflow streamline bundle (Fig 1, Neck-limited). Group U aneurysms had unvisualized inflow streamlines (Fig 1, Unvisualized).

The inflow streamline bundles were not visualized during the diastole phase in any of the 57 aneurysms. The inflow jet pattern of each aneurysm was determined by selecting a stable pattern through the systole phase of the cardiac cycle. Three observers (K.F., F.U., and M.N.) independently recorded the inflow jet patterns; disagreements were settled by consensus.

We compared the inflow hemodynamic parameters among the 4 aneurysm groups. The parameters included the maximum inflow velocity, the maximum inflow rate, the inflow velocity ratio (in percentages) (ie, the ratio of the maximum inflow velocity to the maximum flow velocity in the parent artery), and the inflow rate ratio (in percentages) (ie, the ratio of the maximum inflow rate to the maximum flow rate in the parent artery). The maximum inflow velocity and rate were measured on the section plane corresponding to the aneurysmal orifice. The maximum flow velocity and rate in the parent artery were assessed on the section plane in the parent artery just proximal to the aneurysm. All hemodynamic parameters were measured at peak systole by using a function of the Flova II software. Each numeric value was determined as the mean of 3 measurements performed by one of the authors (K.F.).

Statistical analysis was performed with the Mann-Whitney $U$ test for continuous variables and the Fisher exact test for categoric variables. Differences of $P<.05$ were statistically significant.

\section{RESULTS}

Table 1 shows the inflow jet patterns observed at the different thresholds in the 57 aneurysms. The distribution of the patterns was significantly different at the $60 \%$ and $90 \%$ thresholds $(P=$ $.0468)$. In 16 (28.1\%) of the 57 aneurysms, the inflow jet pattern 

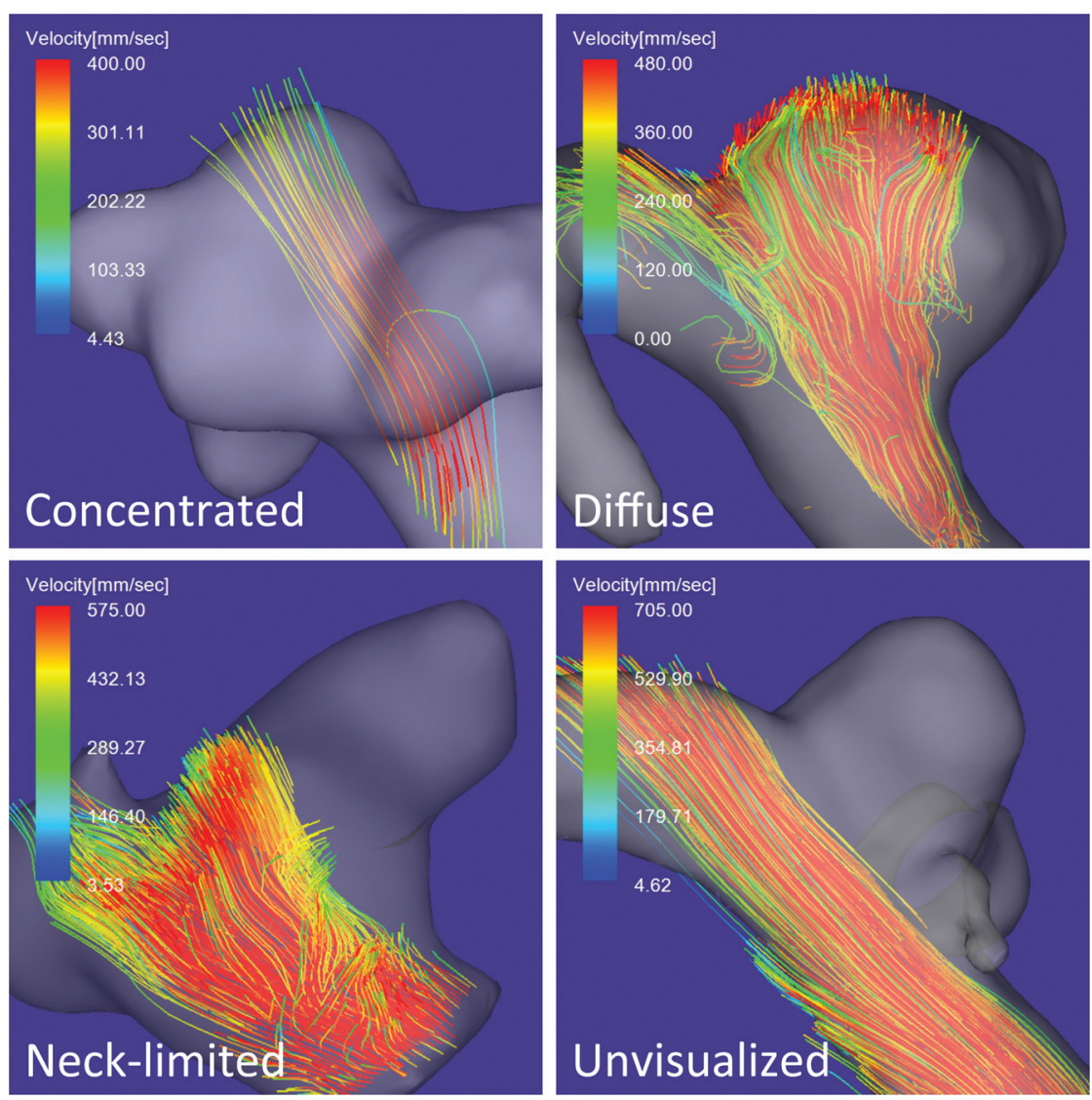

FIG 1. Classification of inflow jet patterns visualized on 4D flow MR images. Concentrated: An aneurysm on the anterior communicating artery with a concentrated inflow jet defined as a bundle of inflow streamlines intruding into the aneurysmal dome without dispersion in $20 \%$ of the width of the streamline bundle at the aneurysmal orifice and impacting the aneurysmal wall at a site more than half-way up the aneurysm height. Diffuse: A sidewall aneurysm on the ICA with a diffuse inflow jet defined as inflow streamlines intruding into the aneurysmal dome with dispersion in $>20 \%$ of the width of the streamline bundle at the aneurysmal orifice and impacting the aneurysmal wall at a site more than half-way up the aneurysm height. Neck-limited: A sidewall aneurysm on the ICA with a neck-limited inflow jet defined as inflow streamlines impacting the aneurysmal wall between the neck and half-way down the aneurysm height. Unvisualized: A sidewall aneurysm on the ICA with unvisualized inflow streamlines defined as no inflow streams into the aneurysm.

Table 1: Inflow jet patterns visualized at the $60 \%, 75 \%$, and $90 \%$ threshold of the maximum velocity in the parent artery ${ }^{\mathrm{a}}$

\begin{tabular}{lccc}
\multicolumn{1}{c}{ Inflow Jet Pattern } & $\begin{array}{c}\text { No. of Aneurysms } \\
\text { (Threshold 60\%) }\end{array}$ & $\begin{array}{c}\text { No. of Aneurysms } \\
\text { (Threshold 75\%) }\end{array}$ & $\begin{array}{c}\text { No. of Aneurysms } \\
\text { (Threshold 90\%) }\end{array}$ \\
\hline Concentrated inflow jet & $8(14.0 \%)$ & $13(22.8 \%)$ & $16(28.1 \%)$ \\
Diffuse inflow jet & $23(40.4 \%)$ & $18(31.6 \%)$ & $14(24.6 \%)$ \\
Neck-limited & $15(26.3 \%)$ & $11(19.3 \%)$ & $9(15.8 \%)$ \\
Unvisualized & $11(19.3 \%)$ & $15(26.3 \%)$ & $18(31.6 \%)$ \\
\hline
\end{tabular}

a The distribution of the inflow jet patterns at the $60 \%$ and $90 \%$ threshold was significantly different $(P=.0468)$.

Because among the 3 thresholds, at $75 \%$, the rate of bifurcation aneurysms was most significantly higher in the concentrated group (group C) than in the diffuse group (group D), we compared the inflow hemodynamic parameters in the 4 groups at the $75 \%$ threshold.

Table 2 shows the maximum inflow velocity and the maximum inflow rate at the $75 \%$ threshold for the different aneurysm groups. The maximum inflow velocity was significantly higher in groups $\mathrm{C}$ and $\mathrm{D}$ than in group $\mathrm{U}$, and the maximum inflow rate was significantly higher than in groups $\mathrm{N}$ and $\mathrm{U}$. There was no statistically significant difference in these values between groups C and D and between groups $\mathrm{N}$ and $\mathrm{U}$.

In Table 3, we present the inflow velocity ratio and the inflow rate ratio at the $75 \%$ threshold for the 4 aneurysm groups. Again, these values were significantly higher in groups $\mathrm{C}$ and D than in groups $\mathrm{N}$ and $\mathrm{U}$, and there was no statistically significant difference between groups $\mathrm{C}$ and $\mathrm{D}$ and between groups $\mathrm{N}$ and $\mathrm{U}$.

\section{DISCUSSION}

4D flow MR imaging makes it possible to assess the flow status in human aneurysms. ${ }^{10-20}$ The hemodynamics (eg, the velocity distribution, inflow streamlines, and flow patterns) determined on 4D flow MR imaging have been validated by computational fluid dynamics studies in human cerebral aneurysms, ${ }^{10,12,14}$ experimental canine aneurysms, ${ }^{25}$ and life-size human aneurysm phantoms. ${ }^{22,26,27}$ The feasibility of visualizing the aneurysmal inflow on $4 \mathrm{D}$ flow MR imaging has been confirmed..$^{9,11,14,17,20,21}$ We used 4D flow MR imaging to evaluate the inflow jet patterns and the inflow hemodynamic parameters in patients with unruptured aneurysms.

was different at different thresholds (Fig 2). Four of 16 aneurysms classified as group C at the $90 \%$ threshold were group D lesions at the $75 \%$ threshold; 3 of these 4 aneurysms were sidewall aneurysms. Of the 13 aneurysms classified as group C at the $75 \%$ threshold, $5(38.5 \%)$ were group D at the $60 \%$ threshold; these 5 were bifurcation aneurysms. Furthermore, 10 of $16(62.5 \%)$ group C and 2 of 14 (14.3\%) group D aneurysms at the $90 \%$ threshold $(P=.0106), 10$ of $13(76.9 \%)$ group $C$ and 2 of 18 (11.1\%) group D aneurysms at the $75 \%$ threshold $(P=.0005)$, and 6 of 8 (75\%) group C and 7 of 23 (30.4\%) group D aneurysms at the $60 \%$ threshold $(P=.0429)$ were bifurcation aneurysms.
At present there is no accepted robust definition of inflow jets. They have been evaluated by visual inspection and characterized by their strongly directed, high-speed flow structure. ${ }^{1,2}$ Schneiders et $\mathrm{al}^{7}$ and Jansen et $\mathrm{al}^{8}$ defined the inflow jet as the top 25\% of the flow magnitude within an aneurysm. However, there may be a considerable difference in the maximum flow magnitude within an aneurysm. In fact, we found that there was a 3.8-fold difference in the mean value of the maximum inflow rate between group $\mathrm{C}$ and $\mathrm{U}$ lesions (Table 2). According to Szikora et $\mathrm{al}^{28}$ and Castro et al, ${ }^{6}$ in ruptured aneurysms, the inflow jet tended to enter straight from the parent artery. Their observation suggests that 

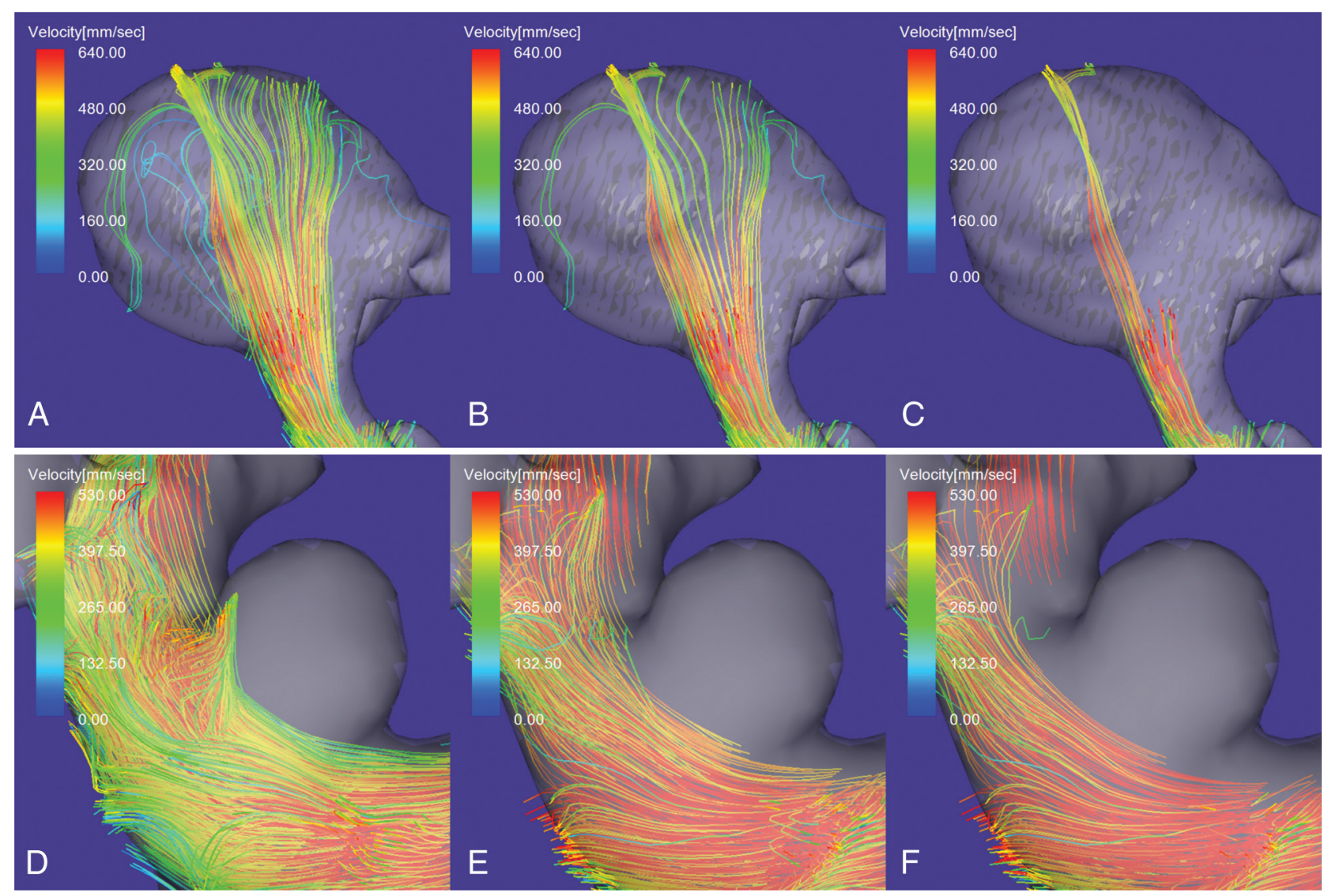

FIG 2. Inflow jet patterns on $4 D$ flow $M R$ images determined by observing the inflow streamline bundle with a velocity exceeding visualization thresholds corresponding to $60 \%(A$ and $D), 75 \%(B$ and $E)$, and $90 \%$ ( $C$ and $F)$ of the maximum velocity in the parent artery. $A-C$, An aneurysm on the ICA segment branching the posterior communicating artery. $D-F$, An aneurysm on the paraclinoid segment of the ICA. $A$ and $B, A$ diffuse inflow jet intruding into the aneurysmal dome. The visualization thresholds are $60 \%(A)$ and $75 \%(B)$. C, A concentrated inflow jet intruding into the aneurysmal dome without dispersion (visualized at the $90 \%$ threshold). $D$, A neck-limited inflow jet visualized at the $60 \%$ threshold. $E$ and $F$, Unvisualized inflow streams - that is, no inflow streams are observed at the $75 \%(E)$ and the $90 \%(F)$ thresholds.

Table 2: Maximum inflow velocity and maximum inflow rate in unruptured aneurysms with different inflow jet patterns visualized at the $75 \%$ threshold of the maximum velocity in the parent artery ${ }^{\mathrm{a}}$

\begin{tabular}{|c|c|c|c|c|c|}
\hline Inflow Jet Pattern & Median (IQR) & Concentrated Inflow Jet & Diffuse Inflow Jet & Neck-Limited & Unvisualized \\
\hline \multicolumn{6}{|l|}{ Concentrated inflow jet } \\
\hline Maximum inflow velocity $(\mathrm{mm} / \mathrm{s})$ & $572(206)$ & & .2539 (NS) & .4689 (NS) & $.0002(S)$ \\
\hline Maximum inflow rate $(\mathrm{mL} / \mathrm{s})$ & $2610(3080)$ & & .8414 (NS) & $.0049(\mathrm{~S})$ & $.0006(S)$ \\
\hline \multicolumn{6}{|l|}{ Diffuse inflow jet } \\
\hline Maximum inflow velocity $(\mathrm{mm} / \mathrm{s})$ & $636(289)$ & .2539 (NS) & & .0963 (NS) & $<.0001(S)$ \\
\hline Maximum inflow rate $(\mathrm{mL} / \mathrm{s})$ & $2450(3080)$ & .8414 (NS) & & $.0017(S)$ & $<.0001(\mathrm{~S})$ \\
\hline \multicolumn{6}{|l|}{ Neck-limited } \\
\hline Maximum inflow velocity $(\mathrm{mm} / \mathrm{s})$ & $462(380)$ & .4689 (NS) & .0963 (NS) & & .2645 (NS) \\
\hline Maximum inflow rate $(\mathrm{mL} / \mathrm{s})$ & $890(424)$ & $.0049(S)$ & $.0017(\mathrm{~S})$ & & .3637 (NS) \\
\hline \multicolumn{6}{|l|}{ Unvisualized } \\
\hline Maximum inflow velocity $(\mathrm{mm} / \mathrm{s})$ & $382(44.0)$ & $.0002(S)$ & $<.0001(\mathrm{~S})$ & .2645 (NS) & \\
\hline Maximum inflow rate $(\mathrm{mL} / \mathrm{s})$ & $696(454)$ & $.0006(S)$ & $<.0001(S)$ & .3637 (NS) & \\
\hline
\end{tabular}

Note:-IQR indicates interquartile range; S, significant; NS, not significant by the comparison test adjusted for the $P$ value.

${ }^{a}$ Statistical analysis was performed between a variable in the left column and a variable in the headers.

the inflow jet should be defined on the basis of the flow magnitude in the parent artery. We assessed the inflow jets on 4D flow MR imaging by using thresholds based on the maximum flow velocity in the parent artery and classified the aneurysms on the basis of the inflow jet pattern.

Szikora et $\mathrm{al}^{28}$ reported that concentrated inflow jets were observed in most ruptured aneurysms and that all aneurysms with such inflow jets were bifurcation aneurysms; none were sidewall aneurysms. We showed that individual inflow jet patterns re- flected the threshold used to visualize the inflow streamlines. Three sidewall aneurysms whose inflow jets were concentrated at the $90 \%$ threshold exhibited a diffuse inflow jet at the $75 \%$ threshold, while 5 bifurcation aneurysms whose inflow jets were concentrated at the $75 \%$ threshold exhibited a diffuse inflow jet at the $60 \%$ threshold. The most significant difference in the rate of bifurcation aneurysms between groups $\mathrm{C}$ and $\mathrm{D}$ was observed at the $75 \%$ threshold. However, there is no evidence that the $75 \%$ threshold is optimal for evaluating the risk for aneurysmal 
Table 3: Inflow velocity ratio and inflow rate ratio in unruptured aneurysms with different inflow jet patterns visualized at the $75 \%$ threshold of the maximum velocity in the parent artery ${ }^{\mathrm{a}}$

\begin{tabular}{|c|c|c|c|c|c|}
\hline Inflow Jet Pattern and Ratio & Median \% (IQR) & Concentrated Inflow Jet & Diffuse Inflow Jet & Neck-Limited & Unvisualized \\
\hline \multicolumn{6}{|l|}{ Concentrated inflow jet } \\
\hline Inflow velocity & $94.1(15.5)$ & & .5222 (NS) & $.0138(S)$ & $<.0001(\mathrm{~S})$ \\
\hline Inflow rate & $89.9(52.3)$ & & .1735 (NS) & $.0059(\mathrm{~S})$ & $<.0001(S)$ \\
\hline \multicolumn{6}{|l|}{ Diffuse inflow jet } \\
\hline Inflow velocity & $101(31.8)$ & .5222 (NS) & & $.0053(S)$ & $<.0001(\mathrm{~S})$ \\
\hline Inflow rate & $59.3(59.9)$ & .1735 (NS) & & .0194 (S) & $<.0001$ (S) \\
\hline \multicolumn{6}{|l|}{ Neck-limited } \\
\hline Inflow velocity & $69.4(28.8)$ & $.0138(S)$ & $.0053(\mathrm{~S})$ & & .0516 (NS) \\
\hline Inflow rate & $29.8(33.3)$ & $.0059(S)$ & .0194 (S) & & .1021 (NS) \\
\hline \multicolumn{6}{|l|}{ Unvisualized } \\
\hline Inflow velocity & $59.1(7.62)$ & $<.0001(\mathrm{~S})$ & $<.0001(\mathrm{~S})$ & .0516 (NS) & \\
\hline Inflow rate & $21.6(16.0)$ & $<.0001$ (S) & $<.0001$ (S) & .1021 (NS) & \\
\hline
\end{tabular}

Note:- IQR indicates interquartile range; $S$, significant; NS, not significant by the comparison test adjusted for the $P$ value; inflow velocity ratio, the ratio of the maximum inflow velocity to the maximum flow velocity in the parent artery; inflow rate ratio, the ratio of the maximum inflow rate to the maximum flow rate in the parent artery.

a Statistical analysis was performed between a variable shown in the left column and a variable in the headers.

growth, bleb formation, or rupture. Long-term observation studies are needed to identify the optimal visualization threshold.

Among the aneurysms in our study, those in groups C and D manifested significantly higher values in the inflow hemodynamic parameters than did group $\mathrm{N}$ and $\mathrm{U}$ lesions (Tables 2 and 3). While there was no statistically significant difference in the maximum inflow velocity, the maximum inflow rates, the inflow velocity ratio, and the inflow rate ratio between groups $C$ and $D$, concentrated inflow jets may exert a stronger impact force on a small area in the aneurysm wall than diffuse inflow jets. Cebral et $\mathrm{al}^{4,5}$ reported that the inflow jets of ruptured aneurysms tended to be concentrated, while unruptured aneurysms manifested diffuse inflow jets that impacted larger areas. However, it remains unclear at what degree of inflow hemodynamic force aneurysmal rupture is likely. On the other hand, others ${ }^{29,30}$ have associated aneurysmal rupture with low-flow conditions as seen in our group $\mathrm{N}$ and $\mathrm{U}$ aneurysms. Our classification of inflow jet patterns and our quantitative estimation of the inflow hemodynamics may be the foundation for further studies investigating risk factors for aneurysmal rupture.

Our study has some limitations. In aneurysms with a low height and a wide neck, the inflow streamline bundle is usually short and wide. This may render it difficult to determine the extent of inflow jet dispersion by visual inspection. To identify risky inflow jet patterns computationally and to avoid subjective judgments, studies to establish numeric values for inflow hemodynamic parameters representing risk factors are needed. 4D flow MR imaging may yield poor-quality images due to motion artifacts attributable to a relatively long acquisition time ${ }^{21}$ and limited spatial resolution. ${ }^{9-14,17,20,22,25-27}$ Because flow quantification by using $4 \mathrm{D}$ flow $\mathrm{MR}$ imaging requires at least 16 isotropic voxels over the vessel lumen area, ${ }^{31}$ a spatial resolution of $1.0 \mathrm{~mm}$ in the isotropic voxel dimensions is needed to evaluate the flow conditions in aneurysms with a diameter of $4.0 \mathrm{~mm} \cdot{ }^{22}$ Although only 1.5T MR imaging scanners are available at our institution, high-resolution MR imaging on greater than 3T instruments may make it possible to evaluate the inflow jets of aneurysms smaller than $4.0 \mathrm{~mm} .^{12-14,17,22}$ While contrast-enhanced 3D cine phasecontrast MR imaging may improve the spatial and temporal resolution, its efficacy for the evaluation of inflow hemodynamics remains to be established. In addition, computational fluid dy- namics analysis can be performed on the basis of the accurate vascular geometry with a motion-free acquisition. Additional studies are needed to understand the effects of novel techniques applied to 3D cine phase-contrast $\mathrm{MR}$ imaging and to validate the evaluation of small aneurysms on $1.5 \mathrm{~T}$ scanners by computational fluid dynamics analysis.

\section{CONCLUSIONS}

The inflow jet pattern may depend on the threshold applied to visualize the inflow streamlines on $4 \mathrm{D}$ flow MR images. Because of the significant difference in the rate of bifurcation aneurysms and in the values of inflow hemodynamic parameters, for a classification of the inflow jet patterns on $4 \mathrm{D}$ flow MR imaging, the $75 \%$ threshold may be optimal within the 3 thresholds corresponding to $60 \%, 75 \%$, and $90 \%$ of the maximum flow velocity in the parent artery.

\section{REFERENCES}

1. Gasteiger R, Lehmann DJ, van Pelt R, et al. Automatic detection and visualization of qualitative hemodynamic characteristics in cerebral aneurysms. IEEE Trans Vis Comput Graph 2012;18:2178-87 CrossRef Medline

2. Neugebauer M, Gasteiger R, Janiga G, et al. Effective visual exploration of hemodynamics in cerebral aneurysms. In: Proceedings of the Conference of the European Association for Computer Graphics, Geona, Spain; May 6-10, 2013

3. Cebral JR, Sheridan M, Putman CM. Hemodynamics and bleb formation in intracranial aneurysms. AJNR Am J Neuroradiol 2010;31: 304-10 CrossRef Medline

4. Cebral JR, Castro MA, Burgess JE, et al. Characterization of cerebral aneurysms for assessing risk of rupture by using patient-specific computational hemodynamics models. AJNR Am J Neuroradiol 2005;26:2550-59 Medline

5. Cebral JR, Mut F, Weir J, et al. Association of hemodynamic characteristics and cerebral aneurysm rupture. AJNR Am J Neuroradiol 2011;32:264-70 CrossRef Medline

6. Castro MA, Putman CM, Sheridan MJ, et al. Hemodynamic patterns of anterior communicating artery aneurysms: a possible association with rupture. AJNR Am J Neuroradiol 2009;30:297-302 Medline

7. Schneiders JJ, Marquering HA, Antiga L, et al. Intracranial aneurysm neck size overestimation with 3D rotational angiography: the impact on intra-aneurysmal hemodynamics simulated with computational fluid dynamics. AJNR Am J Neuroradiol 2013;34:121-28 CrossRef Medline

8. Jansen IG, Schneiders JJ, Potters WV, et al. Generalized versus pa- 
tient-specific inflow boundary conditions in computational fluid dynamics simulations of cerebral aneurysmal hemodynamics. AJNR Am J Neuroradiol 2014;35:1543-48 CrossRef Medline

9. Meckel $S$, Stalder AF, Santini F, et al. In vivo visualization and analysis of 3-D hemodynamics in cerebral aneurysms with flowsensitized 4-D MR imaging at 3 T. Neuroradiology 2008;50:473-84 CrossRef Medline

10. Boussel L, Rayz V, Martin A, et al. Phase-contrast magnetic resonance imaging measurements in intracranial aneurysms in vivo of flow patterns, velocity fields, and wall shear stress: comparisons with computational fluid dynamics. Magn Reson Med 2009;61: 409-17 CrossRef Medline

11. Hope TA, Hope MD, Purcell DD, et al. Evaluation of intracranial stenoses and aneurysms with accelerated 4D flow. Magn Reson Imaging 2010;28:41-46 CrossRef Medline

12. Isoda $\mathrm{H}$, Ohkura $\mathrm{Y}$, Kosugi $\mathrm{T}$, et al. Comparison of hemodynamics of intracranial aneurysms between MR fluid dynamics using 3D cine phase contrast MRI and MR-based computational fluid dynamics. Neuroradiology 2010;52:913-20 CrossRef Medline

13. Isoda $\mathrm{H}$, Ohkura $\mathrm{Y}$, Kosugi $\mathrm{T}$, et al. In vivo hemodynamic analysis of intracranial aneurysms obtained by magnetic resonance fluid dynamics (MRFD) based on time-resolved three-dimensional phasecontrast MRI. Neuroradiology 2010;52:921-28 CrossRef Medline

14. Naito T, Miyachi S, Matsubara N, et al. Magnetic resonance fluid dynamics for intracranial aneurysms: comparison with computed fluid dynamics. Acta Neurochir (Wien) 2012;154:993-1001 CrossRef Medline

15. Kawaguchi T, Nishimura S, Kanamori M, et al. Distinctive flow pattern of wall shear stress and oscillatory shear index: similarity and dissimilarity in ruptured and unruptured cerebral aneurysm blebs. J Neurosurg 2012;117:774-80 CrossRef Medline

16. Kecskemeti S, Johnson K, Wu Y, et al. High resolution three-dimensional cine phase contrast MRI of small intracranial aneurysms using a stack of stars k-space trajectory. J Magn Reason Imaging 2012; 35:518-27 CrossRef Medline

17. van Ooij P, Schneiders JJ, Marquering HA, et al. 3D cine phase-contrast MRI at $3 \mathrm{~T}$ in intracranial aneurysms compared with patientspecific computational fluid dynamics. AJNR Am J Neuroradiol 2013;34:1785-91 CrossRef Medline

18. Schnell S, Ansari SA, Vakil P, et al. Three-dimensional hemodynamics in intracranial aneurysms: influence of size and morphology. J Magn Reson Imaging 2014;39:120-31 CrossRef Medline

19. Berg P, Stucht D, Janiga G, et al. Cerebral blood flow in a healthy circle of Willis and two intracranial aneurysms: computational fluid dynamics versus four-dimensional phase-contrast magnetic resonance imaging. J Biomech Eng 2014;136 CrossRef Medline
20. Futami K, Sano H, Misaki K, et al. Identification of the inflow zone of unruptured cerebral aneurysms: comparison of 4D flow MRI and 3D TOF MRA data. AJNR Am J Neuroradiol 2014;35:1363-70 CrossRef Medline

21. Futami K, Sano H, Kitabayashi T, et al. Parent artery curvature influences inflow zone location of unruptured sidewall cerebral aneurysms. AJNR Am J Neuroradiol 2015;36:342-48 70 CrossRef Medline

22. Hollnagel DI, Summers PE, Poulikakos D, et al. Comparative velocity investigations in cerebral arteries and aneurysms: 3D phasecontrast MR angiography, laser Doppler velocimetry and computational fluid dynamics. NMR Biomed 2009;22:795-808 CrossRef Medline

23. Lorensen WE, Cline HE. Marching cubes: a high resolution 3D surface construction algorithm. ACM Siggraph Computer Graphics 1987;21:163-69 CrossRef

24. Shimai H, Yokota H, Nakamura S, et al. Extraction from biological volume data of a region of interest with nonuniform intensity. In Proceedings of the Society of Photo-Optical Instrumentation Engineers 6051, Optomechatronic Machine Vision, Kauhiko, Sumi, Japan. December 6, 2005; 6051:605115

25. Jiang J, Johnson K, Valen-Sendstad K, et al. Flow characteristics in a canine aneurysm model: a comparison of $4 \mathrm{D}$ accelerated phase contrast MR measurements and computational fluid dynamics simulations. Med Phys 2011;38:6300-12 CrossRef Medline

26. van Ooij P, Guedon A, Poelma C, et al. Complex flow patterns in a real-size intracranial aneurysm phantom: phase contrast MRI compared with particle image velocimetry and computational fluid dynamics. NMR Biomed 2012;25:14-26 CrossRef Medline

27. van Ooij P, Potters WV, Guédon A, et al. Wall shear stress estimated with phase contrast MRI in an in vitro and in vivo intracranial aneurysm. J Magn Reson Imaging 2013;38:876-84 CrossRef Medline

28. Szikora I, Paal G, Ugron A, et al. Impact of aneurysmal geometry on intraaneurysmal flow: a computerized flow simulation study. $\mathrm{Neu}$ roradiology 2008;50:411-21 CrossRef Medline

29. Xiang J, Yu J, Snyder KV, et al. Hemodynamic-morphological discriminant models for intracranial aneurysm rupture remain stable with increasing sample size. J Neurointerv Surg 2016;8:104-10 CrossRef Medline

30. Yasuda R, Strother CM, Taki W, et al. Aneurysm volume-to-ostium area ratio: a parameter useful for discriminating the rupture status of intracranial aneurysms. Neurosurgery 2011;68:310-17 CrossRef Medline

31. Tang C, Blatter CC, Paker DL. Accuracy of phase-contrast flow measurements in the presence of partial-volume effects. J Magn Reson Imaging 1993;3:377-85 CrossRef Medline 